ПОЛУЧЕНИЕ МАСЕЛ С ПРИМЕНЕНИЕМ МЕТОДА ХОЛОДНОГО ПРЕССОВАНИЯ

Фармонов Жасур Байкараевич

ст. преподаватель

Кариинского инженерно-экономического института Республика Узбекистан, г. Карии E-mail:ssamadiy@inbox.ru

Давлатов Фаррух Фарходович

cm. преподаватель Каршинского инженерно-экономического института

Республика Узбекистан, г. Карии

Кодиров Шерзод Мамарасулович ассистент Джиззакского политехнического института

Республика Узбекистан, г. Джиззак

Серкаев Камар Пардаевич nрофессор

Ташкентского химико-технологического института Республика Узбекистан, г. Ташкент

Самадий Муроджон Абдусалимзода зам. директора по наукам и инновациям Янгиерского филиала

Ташкентского химико-технологического института

Республика Узбекистан, г. Янгиер E-mail: samadiy@inbox.ru

\title{
PRODUCTION OF OILS USING THE COLD PRESSING METHOD
}

Jasur Farmonov

Senior teacher of Karshi engineering economical institute, Republic of Uzbekistan, Karshi

Farrukh Davlatov

Senior teacher of Karshi engineering economical institute, Republic of Uzbekistan, Karshi

Sherzod Qodirov

Assistant at Jizzakh Polytechnic Institute Republic of Uzbekistan, Jizzakh

Kamar Serkaev Professor of Tashkent institute of chemical technology, Republic of Uzbekistan, Tashkent

Murodjon Samadiy

Deputy Director for Science and Innovation of the Yangier branch of the Tashkent Chemical-Technological Institute Republic of Uzbekistan, Yangier

Библиографическое описание: Получение масел с применением метода холодного прессования // Universum: технические науки : электрон. научн. журн. Фармонов Ж.Б. [и др.]. $2021 . \quad 5(86) . \quad$ URL: https://7universum.com/ru/tech/archive/item/11689 


\section{АННОТАЦИЯ}

В статье приведены сведения о холодном прессование масличного сырья. Подробно изложены стадии очистки семян от примесей, сортировки, дробления, сушки и прессование.

Было определено влияние времени и температуры «холодного» прессования в химический состав получаемого масла, обсуждены его пищевые и лечебные свойства и области применения.

Представлена технологическая линия, включающая моечную машину, транспортер, сортировочную машину для резки на части плодов дыни, машину для отделения семян, машину для очистки от корки, измельчатель для получения лепестка, сверхкритический экстрактор и упаковочную машину.

Делается заключение о возможности использования метода «холодного» прессования для получения качественных масел с высокими пищевыми и фармакологическими данными, так как для этого имеются все возможности.

\section{ABSTRACT}

The article provides information on cold pressing of oilseeds. The stages of cleaning seeds from impurities, sorting, crushing, drying and pressing are described in detail.

The influence of the time and temperature of "cold" pressing on the chemical composition of the resulting oil was determined, its nutritional and medicinal properties and fields of application were discussed.

Introduced a processing line including a washer, a conveyor, a sorting machine for cutting into pieces of melon fruit, a machine for separating seeds, peeling machine, chopper for obtaining petal, supercritical extractor and packing machine.

A conclusion is made about the possibility of using the "cold" pressing method to obtain high-quality oils with high nutritional and pharmacological data, since there are all the possibilities for this.

Ключевые слова: холодная прессования, горячая прессования, жмых, экстракция, измельчение.

Keywords: cold pressing, hot pressing, cake, extraction, grinding.

В промышленности растительные масла выделяются из семян масличных растений прессованием (холодным или горячим) или экстракцией бензином. Кроме того, применяют комбинированный метод, включающий прессование с последующим экстрагированием масла, оставшегося в жмыхе, жидким растворителем, например бензолом [5].

Холодный отжим является одном из методов прессования без нагревания или при низкой температуре. После холодного отжима масляная температура и масляный коэффициент кислотности низкие. Масло холодного отжима обычно не требует рафинирования, и после осаждения и фильтрации получают готовое масло [6, 12].

Существует специальный винтовой пресс, называемый холодным прессом, где температура подачи семян масличных культур ниже $80^{\circ} \mathrm{C}$, и перед прессом не обжаривается.

Особенности метода холодного отжима:

1. Готовое масло прозрачное после холодного отжима. Если ваши стандарты требования к маслу по цвету строгие, мы рекомендуем Вам выбрать холодный отжим.

2. Качество жмыха отличное. Благодаря отсутствием высокотемпературного процесса, белок в жмыхах сохраняет первоначальное качество и не изменяется даже после пресса. Таким образом, жмых все еще имеет высокую пищевую ценность.

Горячий отжим происходит при температуре подачи масличных семян в пресс выше $80^{\circ} \mathrm{C}$. Как правило, перед прессом имеется одна жаровня, функция которой в основном состоит в том, чтобы регулировать температуру и содержание воды в масличных семенах, повышать температуру масличных семян и увеличивать конечный выход масла.
Особенности метода горячего отжима:

1. Высокая добыча масла. После обжарки и отжима больше масло в масличных семенах получают.

2. Пахнет хорошо. Благодаря высокой температуре жаровни готовое масло пахнет и пробуется хорошо.

3. Низкий остаток масла в жмыхе. После горячего отжима остаточное масло немножко в жмыхах.

Каждая масличная культура имеет свои уникальные свойства. Каждой масличной культуре нужен соответственный метод отжима.

В последние годы начинает находить широкое распространение выработка масла так называемым «холодным» прессованием, при котором вырабатывается масло высокого качества с содержанием полезных натуральных компонентов. Масло «холодного» прессования не требует рафинации, и после очистки готово к употреблению [2].

Обычно для получения растительного масла используется длительное высокотемпературное прессование (в течение 20 мин при $120^{\circ} \mathrm{C}$ ). Такой метод губит полезные вещества, содержащиеся в ядрах масличных семян, в первую очередь, витамин Е и каротин. Первый замедляет процессы старения и препятствует развитию раковых заболеваний. Второй (провитамин А) отвечает за зрение и рост. Кроме того, при длительной температурной и механической обработке в масло переходят многие вредные вещества. Именно для их удаления требуется рафинация и химическая обработка, при которой разрушаются оставшиеся витамины и белки, а также снижается устойчивость масла к окислению в процессе хранения.

Нерафинированное масло, полученное «холодным» прессованием, лучше усваивается, сохраняет больше витаминов и полезных веществ, чем такое же масло, полученное горячим прессованием, и тем более рафинированным. 
Однако, как известно, по содержанию масла зерна многих культур (амаранта и др.) относятся к низкомасличным культурам, с содержанием масла не выше $13 \ldots 14 \%$, и сложность процесса прессования состоит в качественной подготовке сырья с последующим извлечением масла. В большинстве своем прессы предназначены для отжима масла, из сырья масличность которых не ниже 15\%, что делает их непригодными для отжима низкомасличного сырья.

Основной причиной при этом является нарушение технологического процесса формирования гранул из жмыха и вывод их через отверстия фильера из рабочий зоны пресса. К тому же известно, что для нормального функционирование образования гранул в жмыхе должно содержаться не менее 6-8\% жира [7]. Поэтому для обеспечения работоспособности маслопресса «холодного» отжима за счет стабильного формирования и вывода из зоны прессования гранул жмыха, предложен усовершенствованный технологический процесс, заключающейся в том, что низкомасличное сырье подвергаются прессованию в смеси с другим маслосодержащим сырьем при их общей масличности более 15\%.При совместном прессовании извлекаемые из них масло перемешивается и по количественному составу достаточна для формирования гранул, а также вывода через отверстия фильера. Этим же обеспечивается работоспособность маслопресса «холодного» отжима [14]. Необходимое и достаточное количество масла в жмыхе для стабильного формирования гранул обеспечивается тем, что массовые доли смешиваемых сырьевых компонентов должны содержать жира более $15 \%$. Последнее является также условием работоспособности масловыжимных прессов.

Известен способ холодного отжима масла из семян дыни Калахари [1]. Полученное дынное масло используют при производстве кремов для увлажнения, регенерации и очищения кожи лица.

Основным недостатком данного способа является низкий выход масла. Известен способ [3] получения масла из семян бахчевых культур, включающий очистку от сорных примесей, сортировку, дробление, сушку и прессование раздробленных семян. При этом сушку проводят в устройстве шнекового типа для тепловой обработки масличных семян вначале при температуре от $100{ }^{\circ} \mathrm{C}$ до $110^{\circ} \mathrm{C}$ в течение от 2 мин до 3 мин, а затем при температуре не выше $60{ }^{\circ} \mathrm{C}$ в течение от 20 мин до 23 мин до влажности от $3 \%$ до 5 \%. Далее проводят дробление семян до фракции размеров крупного помола.

Прессование раздробленных семян бахчевых выполняют вначале при температуре не выше $50{ }^{\circ} \mathrm{C}$, а затем перед завершением цикла прессования за 8-10 секунд температуру поддерживают в интервале от $80{ }^{\circ} \mathrm{C}$ до $100{ }^{\circ} \mathrm{C}$. Полученное масло имеет повышенное содержание токоферолов, витаминов и других биологически активных веществ.

Основным недостатком данной технологии является отсутствие этапа отделения плодовой оболочки, что не позволяет получить высокопротеиновый жмых.

Подробно рассмотрен метод получения масла из семян косточковых плодов и путем холодного прессования, переработки семян дыни. Оптимальный способ получения высококачественного масла - холодное прессование с использованием непрерывно действующего шнекового пресса $[8,11]$.

Известна технологическая линия по переработке семян дыни [4] (рисунок 1), включающая моечную машину 1 , транспортер 2, сортировочную машину для резки на части плодов дыни 3 , машину для отделения семян 4, машину для очистки от корки 5 , измельчитель для получения лепестка 6 , сверхкритический экстрактор 7, упаковочную машину 8.

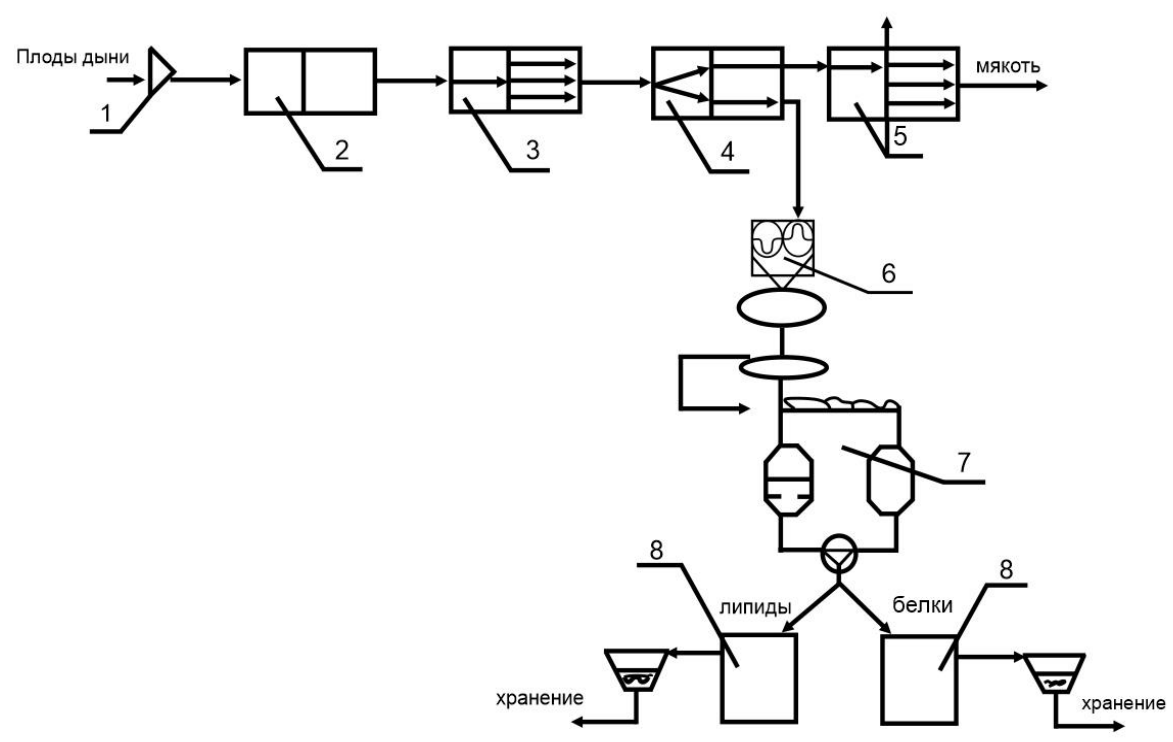

Рисунок 1. Операторная схема технологической линии переработки семян дыни 
Технологическая линия работает следующим образом. Плоды дыни поступают в моечную машину 1 , где происходит инспекционный контроль и затем по транспортеру 2 они подаются в сортировочную машину 3. Здесь плоды дыни разрезаются на части и поступают в машину для отделения семян 4. Затем кусочки дыни, очищены от семян поступают в машину для отчистки от корки 5. Семена дыни отводится в измельчитель 6 , где они измельчаются до лепестка, который подается в сверхкритический экстрактор. В сверхкритическом экстракторе 7, производится процесс сверхкритической экстракции с последующим разделением на белковую и липидную фракции. Далее полученные продукты поступают в упаковочную машину 8 , где они фасуются в асептическую тару и отправляются на дальнейшее хранение.

Основным недостатком данной технологической линии является получение низкопротеинового шрота, а также низкое качество масла, т.к. в процессе $\mathrm{CO}_{2}$ - экстракции извлекаются нежелательные компоненты.

На рисунке 2 представлена структурная схема линии переработки семян бахчевых культур [13].

Технологическая линия состоит из сепаратора для очистки семян от сорных примесей, рифленых вальцов для грубого измельчения семян с получением крупки, вальцового станка для получения мятки, чанной жаровни для влаготепловой обработки мятки, шнекового форпресса для предварительного отжима масла, вальцевого станка для измельчения жмыха, чанной жаровни для влаготепловой обработки измельченного жмыха, экспеллера для окончательного отжима масла, участка первичной отчистки масла, а также транспортирующих конвейеров для перемещения семян, мятки и жмыха.

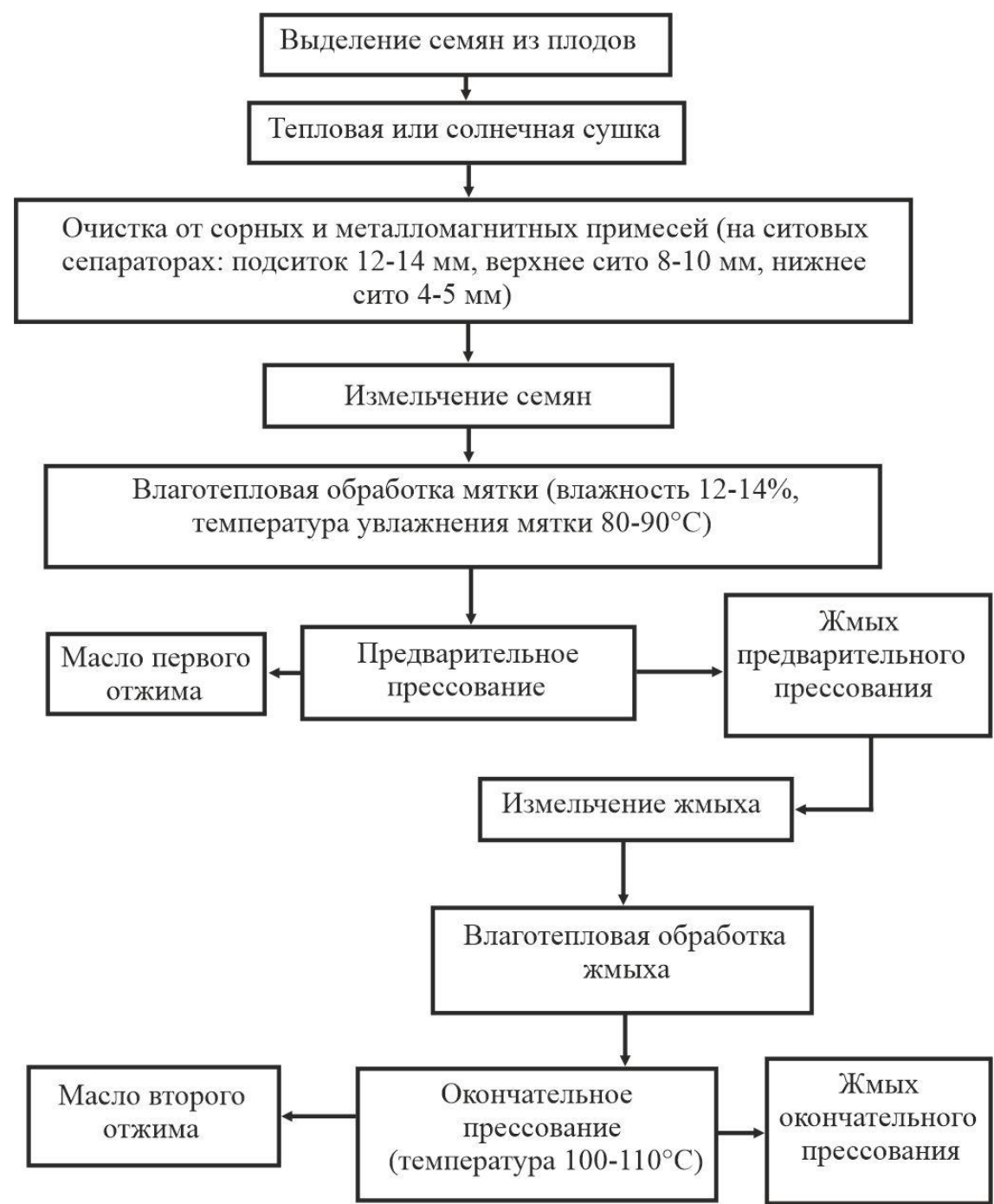

Рисунок 2. Структурная схема переработки семян дыни [9]

Основным недостатком этой технологической линии является многостадийность проведения технологических процессов получения растительного масла из семян дыни, в том числе, двухэтапное измельчение семян и жмыха. Сначала осуществляется предварительное двукратное грубое измельчение семян на рифленых вальцах с получением крупки. Затем проводят измельчение крупки на вальцевых станках с гладкими валками как минимум в два прохода. 
Кроме этого, при подготовке крупки жмыха, необходимой для разрушения внутренней структуры, перед окончательным прессованием (экспеллерном) измельчение осуществляют на вальцевом станке в три - четыре прохода.

В целом такое многоэтапное измельчение обусловливает высокие энергетические затраты.

Не предусмотрен в схеме этап отделения плодовой оболочки, что не позволяет получить высокопротеиновый жмых [10].
Таким образом, результаты исследования по «холодному» прессованию показывают широкое распространение, при котором вырабатывается масло высокого качества с содержанием полезных натуральных компонентов. Масло «холодного» прессования не требует рафинации, и после очистки готово к употреблению.

\section{Список литературы:}

1. Белобородов В.В. Основные процессы производства растительных масел. - М., - 1966г. С. 85-89.

2. Васильева А.Г. Комплексное использование тыквы и ее семян в пищевых технологиях [Текст] / А.Г. Васильева, Г.И. Касьянов, В.В. Деревенко. - Краснодар: Экоинвест, 2010. - 85-99 с.

3. Голдовский А.М. Теоретическое основы производства растительных масел. Пищепромиздат, - М. - 1958. С. 64-71.

4. Драган И.В. Научное обеспечение процесса форпрессования масличных культур и разработка композиций растительных масел функционального назначения: дисс... канд. тех. наук. - Воронеж, 2015. - С. 88-96.

5. Зайцева Л.В. Жиры и масла: современные подходы к модернизации традиционных технологий [Текст] / Л.В. Зайцева, А.П. Нечаев. - М.: ДеЛи плюс, 2013. - С. 35-68.

6. Мирзоев Г.Х. Разработка технологии получения растительного масла и высокопротеинового жмыха из семян дыни [Текст]: дисс... канд. тех. наук. - Краснодар, 2015. - С. 23-27.

7. Нагорнов С.А., Дворецкий Д.С., Романцова С.В., Таров В.П. Техника и технологии производства и переработки растительных масел: учебное пособие // Тамбов: Изд-во ГОУ ВПО ТГТУ, 2010. - С. 5-11.

8. Остриков А.Н. Современное состояние и основные направления совершенствования маслопрессов. Информационный обзор [Текст] / А.Н. Остриков, Л.И. Василенко, М.В. Копылов. - Воронеж ГОУВПО Воронеж, гос. технол. акад, 2011. - С. 40-51.

9. Патент 2179179 Российская Федерация, МПК С11B1/06, С11B1/08. Способ получения масла семян бахчевых культур [Текст] / Чабан Л.Н., Аксененко А.И., Транский М.Б., Шапилов Г.С., Пономарева Т.Д.; заявитель и патентообладатель Межфермерский научно-производственный кооператив «Фармаол», саратовский облпотребсоюз. - № 2000100844/13; заявл. 17.01.2000; опубл. 10.02.2002. Бюл № 10. - 6 с.

10. Патент на ПМ 94419 Российская Федерация, МПК А23N 15/00. Технологическая линия по переработке семян дыни [Текст] / Франко Е.П., Касьянов Г.И., Щербаков В.Г.; заявитель и патентообладатель Кубанский государственный технологический университет. - № 2009136194/22; заявл. 29.09.2009; опубл. 27. 05.2010. - 5 с.

11. Фершау Е. Оборудование для децентрализованного «холодного» прессования масличных семян. 2000 г. (Анг. яз). C. 114-119.

12. Франко Е.П. Семена дыни - перспективный источник растительных масел [Текст] // Известия вузов. Пищевая технология. - 2009. - №2-3. - С. 15-17.

13. Шояисв С.С. Масло сливовых косточек // Масла и жиры. - 2018. - № 1-2. - С. 15-16.

14. Шояисв С. С. Технологии производства масла из косточковых культур // Масла и жиры. - 2018. - Л 1-2. C. 17-19. 